\title{
TERRITÓRIO USADO E FEDERAÇÃO: ARTICULAÇÕES POSSÍVEIS
}

\author{
MáRcio CATAIA*
}

\begin{abstract}
RESUMO: O território não se constitui em categoria de análise, a categoria é o território usado, porque socialmente usado ele revela-se inclusivo, confundindo-se com o espaço banal, o espaço de todos: empresas, instituições e pessoas, em que as coexistências são autorizadas pela contiguidade e solidariedade orgânica. É assim que se pode pensar outra Federação, na medida em que a base desta, o território, possa ser interpretada não como o espaço de exercício do Estado e dos grandes agentes hegemônicos da economia, mas como espaços que sustentam e explicam o conjunto de ações localizadas e interdependentes.
\end{abstract}

Palavras-chave: Território usado. Federação. Lugar. Centralização. Descentralização.

\section{USED TERRITORY AND FEDERATION: POSSIBLE ARTICULATIONS}

ABSTRACT: Territory does not constitute a category of analysis, the category is used territory, because - when used socially - it is shown to be inclusive, mingling with ordinary space, the space of all: companies, institutions and people, where coexistences are authorized by organic solidarity and contiguity. This is how one can consider another federation, to the extent that the base of the federation - the territory - can be interpreted not as the space of exercise of the State and the major hegemonic agents of the economy, but rather as spaces that support and explain the set of localized and interdependent actions.

Key words: Used territory. Federation. Place. Centralization. Decentralization.

\section{TERRITOIRE UTILISE ET FÉDÉRATION: ARTICULATIONS POSSIBLES}

RÉSUMÉ: Le territoire ne se constitue pas comme catégorie d'analyse, la catégorie est le territoire utilisé, car socialement utilisé il se révèle inclusif, tout en se confondant avec l'espace banal, l'espace de tous: les entreprises, les institutions et les individus, où les coexistences sont autorisées par la proximité et par la solidarité organique.Voilà comment l'on peut penser une autre

\footnotetext{
Departamento de Geografia da Universidade Estadual de Campinas (Unicamp). Campinas (SP) Brasil.

Contato com o autor: <cataia@ige.unicamp.br>
} 
Fédération, dans la mesure où le territoire, la base de la Fédération, peut être interprété non seulement comme l'espace de l'exercice de l'État et des grands agents hégémoniques de l'économie, mais aussi comme les espaces qui soutiennent et expliquent l'ensemble d'actions localisées et interdépendantes.

Mots-clés: Territoire utilisé. Fédération. Lieu. Centralisation. Décentralisation.

\section{Introdução}

$\mathrm{H}$ á alguns anos, fenômeno datado desse início de século, tem emergido uma interpretação social crítica sobre o desenvolvimento das sociedades nos países periféricos que incorpora em suas formulações a categoria território. Há, certamente, muitas maneiras de refletir sobre um conceito que é prolífico e prolixo, multidirecional e pluritemático, e uma delas, numa perspectiva geográfica, refere-se ao território usado, praticado, tal como proposto por Santos (1994). O território usado é o território de todos os agentes, de todas as instituições e de todas as empresas, e não apenas o espaço dos agentes hegemônicos da política e da economia.

A sociedade e o território não são duas entidades dissociadas. Numa perspectiva geográfica, procuramos afirmar a indissociabilidade entre materialidades e ações ou, em outras palavras, entre território e política. A categoria "usado", "praticado", altera o significado histórico da categoria "território político" nascido com a Paz de Westphalia (de 1648), ou seja, aquele de matéria inerte, circundada por fronteiras, onde o soberano exerce seu poder. Portanto, o "território político" foi historicamente construído negando à sociedade o seu uso. Desde o nascimento do Estado territorial, a sociedade é deixada de lado, com se existisse uma cisão entre, de um lado, as materialidades - aí incluindo o território político, espaço de exercício do poder do soberano - e, de outro lado, ações sociais, como se estas pudessem ser realizadas isentas às materialidades. Contudo, essa cisão epistemológica entre território e política, que nasce com o Estado territorial e a vontade do Soberano de ser a única fonte de poder sobre o "seu" espaço, teve a função ideológica de revelar o território apenas como forma, não deixando transparecer sua condição de forma-conteúdo, ou seja, negando ao conjunto da sociedade seu protagonismo e seu direito ao espaço, obnubilando o caráter histórico do território, que é resultado de um processo de "formação territorial", e empobrecendo o conceito ao concebê-lo como mero reflexo das ações sociais.

Essa dicotomia, que coloca a sociedade de um lado e o território de outro, impede a compreensão do território usado como um condicionante social, na medida em que o território usado também é, ao lado da política, da cultura e da economia, uma esfera social. 
Também são do final do século XX reflexões sobre a crise da Federação brasileira. Avalia-se que as articulações entre os entes da Federação são mais competitivas que cooperativas. Por isso, estaríamos vivendo um momento de redefinições políticas para o enfrentamento das desigualdades entre os lugares. A Federação é um arranjo político que permite que cada ente e cada lugar tenham uma participação solidária no conjunto da nação. Com isso, o território tem papel ativo na constituição da arquitetura política nacional. De fato, as desigualdades sociais não decorrem de divisões político-administrativas. Contudo, o exercício da cidadania é profundamente impactado pela distribuição das infraestruturas, e estas estão intimamente ligadas aos recortes estaduais e municipais. Como afirma Santos (1993), o cidadão não vale só por sua localização na escala social, mas também por sua localização no espaço; mesmo que, de um ponto de vista legal, os direitos sejam assegurados a todos, independentemente de onde estejam; eles não poderão ser plenamente usufruídos sem uma forte base infraestrutural estadual e municipal.

Este texto reflete sobre os nexos entre território usado e Federação. Ele está organizado em três partes: a primeira - "Território usado como categoria de análise" defende o território usado como categoria de análise e não o território em si; a segunda parte - "Articulações federativas: centralização e descentralização" - reflete sobre a convivência, nas políticas públicas, de processos simultâneos de centralização e descentralização; por fim, a terceira parte - "A federação como sistema de ações" - propõe compreender a Federação a partir do sistemismo das ações dos poderes públicos e dos agentes "periféricos" que, apesar de serem institucionalmente externos aos poderes públicos (União, estados e municípios), têm poder para alterar as políticas estatais.

\section{Território usado como categoria de análise}

Diante da mobilidade generalizada que, no início dos anos de 1980, a globalização pregava, especialmente afirmando a dissolução do espaço pela aceleração do tempo, muitos autores vão reafirmar a importância do território e denunciar as ideologias sobre o seu fim. É nesse momento que Corboz (1983), recenseando as definições do termo segundo diversas disciplinas, afirma que "o território está na moda", sugerindo a centralidade do território nas discussões sobre um novo período histórico que começava a se apresentar após os trinta anos gloriosos de crescimento econômico no centro do sistema capitalista.

Ao refletir sobre o novo mapa do mundo que surgia com a globalização, Santos (1994) propõe o "retorno do território", afirmando que estávamos passando de uma concepção pura, herdada da Modernidade incompleta, para uma interpretação centrada no uso social que se faz do território, daí o autor afirmar que é o uso do território, e não o território em si mesmo, que faz dele objeto da análise social. 
O território "puro", interpretado como uma configuração física circundada por fronteiras políticas no interior das quais o Estado exerce seu poder e soberania, é criticado por muitos motivos, entre eles, um mais propriamente geográfico merece ser destacado: o Estado nunca foi, de fato, a única fonte do poder a usar o território. Raffestin (1993) critica a geografia (política) por ter, durante muito tempo, concebido o Estado como uma instância apartada das contradições sociais, interpretado a partir do "projeto moderno de purificação" (LATOUR, 1994), como um conceito puro. Esse Estado purificado seria a única fonte do poder a dispor do "seu" território. Todavia, Braudel (1995) afirma que a economia "ilegal" que atravessa as fronteiras políticas dos territórios foi, por longos períodos, muito mais importante que a economia "legal". Durante muito tempo, a hegemonia do Estado em usar o território, reclamando para si o monopólio da violência, tornou invisível todos os outros agentes não hegemônicos que também usam o território. Essa geografia do Estado como única fonte do poder, na qual o território é concebido como plataforma de exercício de poderes hegemônicos - para quem o território é um trunfo, um recurso - é reinterpretada em favor de outra concepção de território: aquele usado por todos os agentes.

Não se trata de negar o poder dos agentes hegemônicos. A leitura do território como condição material do Estado moderno, ou seja, de sua soberania na defesa de uma determinada sociedade, permanece fundamental e indispensável, principalmente diante dos conflitos associados à exploração dos recursos territoriais estratégicos e à valorização diferencial dos territórios pela atualização do capitalismo. A questão é que, paralela a essa leitura, emerge outra compreensão do território, expressiva da vida de relações, mais próximo da sociedade civil, ou das nações que compõem as sociedades nacionais (RIBEIRO, 2005).

De uma categoria discursivamente exclusiva do Estado, migramos para uma categoria inclusiva, porque o território usado confunde-se com o espaço banal ${ }^{1}$ (SANTOS, 1996), pois este é referido ao conjunto de todos os indivíduos, todas as empresas e todas as instituições, independentemente do tamanho do poder de cada um. $\mathrm{O}$ território usado é um híbrido de materialidades - a configuração territorial incluía natureza herdada e as artificialidades resultantes do trabalho social -, ações sociais, vida social.

Trata-se do território - a configuração territorial - mais todas as obras que sucessivamente o trabalho social superpõe a ele. Assim construído, ele é um território usado, que abriga ações passadas cristalizadas em objetos e normas, e ao mesmo tempo abriga ações atuais que estão em processo de realização em cada lugar. É trabalho vivo se dando sobre trabalho morto. Contudo, este não é matéria inerte, passiva, mas humanizado pelo trabalho social, impõe-se como normas às ações sociais, não excluindo as ações provenientes dos agentes hegemônicas. Para Silveira (2011, p. 81), objetos e normas nos vêm do passado. Por isso, poderíamos adotar um princípio: “[...] 
território usado, mas como as ações presentificam, trazem novos conteúdos e criam novas resistências, um gerúndio é de rigor: território sendo usado. Nesse sistema de ações, o futuro se instala e o território se torna, ainda mais, um híbrido".

O território usado condensa ações pretéritas e interage com os atores sociais, favorecendo ou negando novas ações. Nesse sentido, o território significa mais do que apenas a inclusão das condições materiais da ação nas circunstâncias do Homem, especialmente porque ele oferece aos vivos a interlocução necessária à realização de futuros desejados (RIBEIRO, 2011). Por isso, o uso do território é pedagógico.

Usado em cada uma de suas frações, o território é um quadro de ação que exerce um papel de condicionamento sobre toda a sociedade. Para Santos (1996), as ações não se geografizam indiferentemente. Em cada momento há uma relação entre o valor das ações e o valor do lugar em que elas se realizam; se não fosse por isso, todos os lugares teriam o mesmo valor de uso e o mesmo valor de troca, ou seja, os valores não seriam afetados pela história sendo feita. As ações não têm o mesmo resultado segundo a fração do espaço onde se instalam.

O movimento da história, em cada lugar, constitui situações geográficas que não se deixam aprisionar pelos limites político-administrativos do território "do Estado", pois os fluxos orientados pelas redes ultrapassam esses limites de solidez variável. O desafio para a governabilidade - incluindo as políticas públicas - das vidas políticas nacional, estadual e municipal resulta do fato de que cada um desses compartimentos acolhe e precipita feixes de variáveis internas e externas, as quais, como regra, não se reduzem a instituições espacialmente circunscritas. Em outras palavras, o território usado - social, econômica e culturalmente - não se reduz à divisão político-administrativa do território nacional. "Reduzir uma região ao seu status político-administrativo, sem considerar que o sistemismo dos objetos e ações ultrapassa seus limites e que os agentes têm força desigual, pode tornar ineficaz uma política pública" (SILVEIRA, 2011, p. 96).

Também é nesse sentido que Ribeiro (2011) alerta para o excesso de referência ao território quando são buscadas maneiras de traçar políticas públicas. $\mathrm{O}$ território é tomado como uma espécie de tradução operacional das estruturas e desigualdades sociais, como se o território, em si mesmo, fosse portador de promessas de intervenções mais generosas no tecido social. São obnubiladas a dinâmica entre abundância e escassez e a natureza mesma da política e da economia, ou seja, do poder, que é multiescalar: as ações dominantes não obedecem a fronteiras e escalas. Reduzir a vida de relações, que por princípio é coletiva e inclui a todos, a uma única dimensão do espaço - o território "dos" agentes hegemônicos da política e da economia - pode implicar a intensificação dos mecanismos de controle social. Ao colar as identidades culturais aos 
elementos imediatamente visíveis da paisagem político-administrativa, restringe-se o mapeamento de determinantes das desigualdades sociais.

\section{Articulações federativas: centralização e descentralização}

Para Fiori (1995), as formas jurídico-constitucionais ou político-institucionais (forma federal ou unitária) que organizam o poder dos Estados nacionais derivam do processo de negociação entre os membros e, sobretudo, de sua correlação de forças em cada momento de negociação. $O$ federalismo é uma forma de organização territorial do poder na qual a tensão e a desarmonia entre as partes são imanentes. A desarmonia está na origem das tensões. Contudo, ela também é a razão das negociações que são permanentes e cujos produtos serão sempre arranjos institucionais provisórios e, por isso, sempre transitórios. Eis aqui os pactos.

Para Castro (2003), o pacto federativo é um acordo de base territorial, no qual lugares e regiões são organizados buscando harmonizar suas demandas endógenas com interesses gerais da sociedade, ou seja, com as demandas por igualdades jurídicas entres todos os membros da sociedade nacional. Por se tratar de acomodação de diferenças, há uma constante tensão nesse pacto, cabendo aos arranjos institucionais organizar os interesses e controlar os conflitos.

A história do Brasil também é a história da sucessão de pactos territoriais. Províncias, cidades e vilas foram impostas como compartimentos territoriais do estatuto imperial depois do abandono do estatuto colonial. A República implantou o federalismo e criou estados e municípios com o discurso da nação descentralizada. A Revolução de 1930, que resultou de conflitos regionais contrariados, constituiu um novo arranjo político-territorial, mas foi substituído por um novo pacto com o Estado Novo e a Constituição de 1937, especialmente suprimindo as autonomias estaduais e mutilando a Federação. A queda de Vargas e a Carta Magna de 1946 resultaram de um novo pacto que buscou restaurar os direitos dos estados federados e, pela primeira vez, o município passa a fazer parte constitucionalmente da Federação (SANTOS, 1993; CATAIA, 2001). O Golpe de 1964 é outro momento em que a construção da nação toma um novo rumo - a construção da nação é interrompida (FURTADO, 1992) - com extrema centralização do poder no Executivo federal. A Constituição de 1988 foi a ocasião para retomar as prerrogativas estaduais e municipais, com a instituição de um federalismo único, já que o Brasil é talvez a única Federação do mundo a ter três esferas de poder: União, estados e municípios.

A partir da década de 1950 tornou-se usual, especialmente entre os geógrafos políticos, interpretar a história política brasileira tendo como referência o movimento entre sístoles e diástoles (COUTO E SILVA, 2003), ou seja, sucessivas fases de alternância entre centralização e descentralização do poder. 
Na década de 1990, depois da promulgação da Constituição "municipalista", ao fazer uma interpretação mais comprometida com as forças democráticas e de esquerda no Brasil, Fiori (1995) retoma a ideia da alternância de fases, trazendo para o centro da discussão social a teoria econômica de Vilfredo Pareto. Segundo essa teoria, a história político-administrativa das nações passa por fases alternadas entre centralização e descentralização do poder, tal qual um pêndulo que se move de um lado para outro, encontrando no movimento pendular o seu equilíbrio e não na estabilidade de uma das pontas. A interpretação de Fiori (op. cit.) passa a ser aceita e difundida a tal ponto que podemos dizer que ela se constituiu num certo paradigma até meados da última década.

Também é da década de 1990 a tese de Abrúcio (1998) de que o federalismo brasileiro estaria entre os mais descentralizados do mundo, o que conferiria excessiva autonomia aos governos subnacionais, especialmente aos estados, limitando incentivos de cooperação dos estados entre si e dos municípios entre si, tendo como consequência relações intergovernamentais predatórias com ausência de coordenação, em um federalismo tipificado como autárquico. Esta tese, a de um "federalismo autárquico", também exerceu e ainda exerce certa supremacia explicativa, especialmente pelo fato de a análise empírica argumentar a descentralização e o poder dos governadores.

A Constituição de 1988 determinou perdas de receita para a União. Desde então, a União tem se movimentado na direção da recomposição de receitas com base em estratégias fiscais. Por isso, muitos interpretam essa oscilação como recentralização do poder (KUGELMAS; SOLA, 2000; CARDOZO, 2004; AMARAL FILHO, 2008; LOPREATO, 2011). O reconhecimento da existência de estratégias fiscais afetou as pesquisas a tal ponto que transformou a fiscalidade em tema obrigatório nos trabalhos sobre o federalismo (o "federalismo fiscal"). Assim, a década de 1990 e a seguinte foram marcadas por pesquisas que avaliavam as consequências das estratégias fiscais, especialmente a guerra fiscal travada entre estados, basicamente manipulando o Imposto sobre a Circulação de Mercadorias (ICMS), e entre municípios, com as isenções de Imposto Sobre Serviços (ISS) (VIEIRA, 2012). Estas pesquisas, que ainda têm enorme influência explicativa nas Ciências Sociais, desenvolvem-se no âmbito da Economia e do direito, especialmente o tributário.

A atualização desse debate é fundamental, especialmente porque o Brasil sofreu intensa influência da proposição de "controle local", que derivou do "new federalism" norte-americano pós-Reagan. Como afirma Markusen (2005), a transferência de poderes aos governos locais é uma prescrição insidiosa adotada por governos nacionais e organizações internacionais conservadoras, como o Banco Mundial e o Fundo Monetário Internacional, para transferir responsabilidades sociais para níveis de governo inferiores, especialmente em países em desenvolvimento, sem recursos ou capacidade técnica para exercê-las. 
Para Harvey (2005), o poder de organização da vida local muitas vezes está em outra parte, ou em coalizões de forças mais amplas, em que o governo e a administração locais desempenham apenas papel facilitador e coordenador. Por isso, a atenção não deve ser dirigida apenas ao governo local. Gottdiener (1993, p. 266) afirma que certos centros comerciais podem ser autossuficientes como escoadouros de mercado, "mas tal pensamento horizontalmente forçado ignora importantes ligações verticais de cada lugar com sistemas hierárquicos de organização capitalista global". Não existem sistemas locais autárquicos, porque as negociações realizadas entre agentes que têm interesses com as possibilidades de desenvolvimento dos lugares só raramente são feitas apenas com agentes locais, sem atores nacionais e globais. Dificilmente empresas globais irão se mover como um ator local, mas estão no lugar ou agem sobre ele a distância. Por isso, o que se passa nos lugares está, em boa medida, condicionado por processos que não são locais. Especialmente nos municípios, como afirma Brandão (2008), a solução de vários problemas extrapola as suas fronteiras jurídicoadministrativas. De fato, políticas públicas centradas em uma única escala, ou em uma esfera de poder, tendem a ser inócuas (VAINER, 2001).

Mais recentemente, algumas pesquisas (GALLO, 2011; ARRETCHE, 2012) trouxeram argumentos bastante convincentes de que o federalismo brasileiro é marcado por uma "coexistência" temporal de complexos processos de centralização e descentralização do poder de realização (regulação e execução) das políticas públicas. Estas têm um processo de regulação centralizado na União e, assim, os ministérios têm poder para estabelecer programas nacionais, ao passo que os entes subnacionais exercem a descentralização política quando executam as políticas públicas preconizadas nestes programas. Nesses termos, centralização e descentralização saem do centro das relações intergovernamentais e passam a orbitar em torno dos eixos da regulação e da execução (ARRETCHE, 2012) das políticas públicas. Portanto, nessa concepção reguladora-executiva coexistem, em uma mesma política pública, centralização e descentralização.

A tese de Arretche (op. cit.) comporta uma base explicativa sólida do funcionamento do federalismo brasileiro. Contudo, por mais paradoxal que pareça, tanto aqueles que buscam provar a (re)centralização do poder, quanto aqueles que buscam dados comprobatórios da descentralização - como foi o caso de Abrúcio (1998) -, tiveram e têm campo aberto às argumentações, se não considerarem o funcionamento sistêmico dos dois polos, "centralização/descentralização", e se forem desconsideradas as especificidades de cada política pública. O caso da saúde é exemplar, porque ainda que exista um sistema descentralizado (o Sistema Único de Saúde - SUS) não se pode praticar atenção básica à saúde nos municípios sem uma regulação nacional - e que, portanto, imponha sua universalização - que permita igualdade de acesso, tratamento e dispensação de medicamentos. 
Assim, é convincente a tese da convivência de elementos centralizadores e descentralizadores. A razão reside no fato de que qualquer política pública da União precisa garantir isonomia a todos os entes subnacionais (26 estados, mais o Distrito Federal e 5.570 municípios). Por isso, ela precisa, necessariamente, ser regulada de maneira centralizada; todos têm direitos universais, como saúde e educação, independentemente do lugar onde habitem - a regulação desses direitos universais não poderia ficar a cargo de cada um dos 5.570 municípios, sob pena de fragmentação da cidadania. Por esta razão, a engenharia política federativa implica um ente que regula e outros que executam.

A convivência de mecanismos de centralização e descentralização é a originalidade do federalismo, que reconhece a existência de regulações que precisam ser nacionais e execuções que forçosamente serão subnacionais, especialmente em um país de dimensões continentais com expressivas diferenciações regionais. $\mathrm{O}$ federalismo incorpora em sua formulação aquele princípio do poder enunciado por Raffestin (1993): o de que, para ser exercido, ele precisa ser dividido. A questão - ou nos termos de Raffestin (op. cit.), a "problemática" - para o exercício do poder reside na inteligência do que concentrar e do que dividir. Introduzir a dimensão do poder nas relações intergovernamentais tem a vantagem de afastar a abordagem formalista estática das "competências" dos entes e aproximar uma abordagem dinâmica dos entes da Federação, pensados segundo o território usado e não como meras divisões político-administrativas moldáveis de acordo com os cortes das políticas públicas.

Porém, o exercício da cidadania é condicionado pelo fato essencial de que os municípios não são iguais. A desigual distribuição regional do aparato infraestrutural afeta o exercício das atividades cotidianas. É por isso que o cidadão não vale só por sua localização na escala social, mas também por sua localização no espaço (SANTOS, 1993), e mesmo que de um ponto de vista legal os direitos sejam assegurados, eles não podem ser plenamente usufruídos sem uma forte base infraestrutural estatal (CASTRO, 2003). Assim, "é na dialética da igualdade jurídica e desigualdade fática que se fundamenta a tarefa do Estado social de atuar no sentido de garantir as condições de vida - em termos sociais, tecnológicos e ecológicos - que tornam possível um uso igualitário dos direitos civis divididos de modo igual" (HABERMAS, 2001, p. 83-84).

A igualdade relativa aos direitos universais exige regulação centralizada, porque a cidadania não é subnacional, mas o seu exercício é afetado pela vida de relações local, ou, em outras palavras, o uso do território se realiza nos lugares (SANTOS; SILVEIRA, 2001). Nestes nexos, entre o nacional e o local, os atores subnacionais não estão paralisados à espera das ordens do nível superior, eles se movimentam no sentido de maior partilha do poder e, por isso, as relações federativas são tensas e constantemente movidas a negociações e pactos. 
Por esta razão, o território usado, praticado, é conflitivo e tem centralidade no debate federativo. O território seletivamente usado tensiona a política, desarmoniza antigos pactos e condiciona a ação política. Ele tem um papel ativo na constituição dos pactos sociais, daí poder-se falar em pactos socioterritoriais. Em um movimento dialético, o território ativo condiciona a ação política, ao mesmo tempo em que as políticas públicas reconfiguram o território.

Para Brandão (2011), uma visão integrada da ação do Estado (em seus três níveis de governo) precisa avançar no Brasil para que se possam avaliar processos e mecanismos de transferências de atribuições e delegações de tarefas, qualificando os graus de transferência espacial de decisões, em uma espécie de "des ou re-hierarquização" de relações intergovernamentais que lograria mudanças nas estruturas e estratégias de redistribuição territorial de poder. Essa abordagem estuda os modos particulares de reordenamento espacial do poder estatal.

Dessa forma, é fundamental colocar no centro da análise o poder de decisão de agentes estatais e "poderes periféricos", que operam nas disputas em torno da produção dos espaços locais, e qualificar as novas formas de produção social e política do território, colocando as questões do poder do Estado - dos agentes hegemônicos - e agentes não hegemônicos no centro da análise e da ação.

\section{A Federação como sistema de ações}

Partimos do pressuposto de que o território usado, sinônimo de espaço geográfico, pode ser definido como um conjunto contraditório e solidário de sistema de objetos e sistema de ações; não se trata de sistema de objetos, nem de sistema de ações tomados isoladamente, mas de um conjunto solidário (SANTOS, 1996, 2000a). De fato, não há exercício dos direitos sociais sem uma forte base infraestrutural, como no caso da saúde, com sua rede de atendimento hospitalar e suas unidades básicas de atendimento, e no caso da educação, com sua rede física de escolas. Objetos e ações, duas categorias indissociáveis, permitem um tratamento analítico das características próprias de cada uma, dando conta da multiplicidade e diversidade das situações particulares e dos processos gerais.

Se a análise das materialidades permite considerar o sistema de objetos organizado segundo divisões territoriais do trabalho, a análise concomitante das relações intergovernamentais possibilita compreender o poder público como um sistema de ações. De um lado, os sistemas de objetos condicionam a forma como se dão as ações e, de outro, o sistema de ações leva à criação de objetos novos ou se realiza sobre objetos preexistentes, reconfigurando sua forma e dando-lhes novos conteúdos. 
O complexo sistema de relações federativas pode ser interpretado como "sistema de ações" (SANTOS, 1996) conjuntamente ao sistema de objetos. Assim fazendo, colocamos o território usado no centro analítico do sistema político federativo.

Um município, em uma definição mais estreita, é uma unidade administrativa ou, em uma definição mais ampla, uma unidade política. Ao lado da Prefeitura, em que é concentrado o Poder Executivo local e todo o corpo administrativo (indicados e concursados), assenta-se a Câmara de Vereadores e também seu corpo administrativo (Legislativo). Para os municípios milionários e as capitais, ainda soma-se um Tribunal de Contas do município, em que se encontra um corpo técnico, qualificado para as contas municipais e para as legislações orçamentárias, que tem a função de fiscalização do orçamento local. Do ponto de vista político e administrativo, que tem a ver com as decisões de ordem coletiva, o município é, na prática, um conjunto complexo composto por um grande número de eleitos, de servidores administrativos, de eleitores, de grupos e associações de pressão local, em que são tomadas inúmeras decisões que provêm: da Prefeitura, da Câmara de Vereadores, das associações de moradores, dos movimentos sociais, dos sindicatos, dos conselhos municipais (saúde, educação etc.), das associações patronais etc.

Crozier e Friedberg (1977) propõem considerar tal conjunto municipal como um "sistema de ação concreto". Do ponto de vista da lógica administrativa isso pode não parecer evidente, porque muitas medidas de coordenação tomadas regularmente surtem pouco efeito e cada agente se fecha sobre suas próprias unidades nas quais, aparentemente, falta comunicação com o conjunto. Mas um exame mais próximo das diversas unidades - dos agentes - permite observar que elas são interdependentes e que as resistências à coordenação das cúpulas resultam do fato de que todos fazem parte de um sistema, quer seja para cooperar, quer seja para resistir.

Como notou Grémion (1976), existem diferenças de fluidez comunicacional segundo os tipos de agentes que são colocados em relação em um sistema de ação concreto. Assim, para o caso francês, o autor observou que as comunicações são mais fáceis quando estabelecidas entre burocratas e notáveis (as elites locais francesas) do que entre burocratas e técnicos no interior da pirâmide hierárquica de uma Prefeitura. Entre notáveis e burocratas são estabelecidas cumplicidades fundadas sobre experiências comuns, comportamentos sociais idênticos e interesses complementares. Ou seja, a pressão do sistema de ação, em certos casos, é mais forte que aquelas das organizações administrativas oficiais.

No entanto, diferentemente da França, onde o sistema político nacional é unitário e, portanto, existe apenas um sistema de ação (nacional centralizado) e muitos "poderes periféricos" departamentais e locais, no caso do Brasil somos levados a reconhecer a Federação - tomada aqui como sinônimo de poder público - como um 
sistema de ação e cada um de seus membros (União, estados e municípios) como subsistemas do sistema de ação federativo, cada um tendo sua esfera própria de ação. Assim, cada ente da Federação é um subsistema do sistema de ação federativo e em cada um deles orbitam "poderes periféricos" ou "poderes laterais" (GRÉMION, 1976; SASSEN, 2010) e "elites do poder" (MILLS, 1962; BURZTYN, 1987; CASTRO, 1992; FAORO, 2000), que, apesar de não serem membros da estrutura hierárquica interna de cada ente da Federação, fazem parte do sistema, porque têm poder para interferir na regulação e execução da renovação das materialidades, redesenhando assim a divisão do trabalho local.

Estamos usando o termo "poder periférico", ou "poder lateral", com base em Sassen (2010), para denominar as muitas fontes do poder que não "se localizam" no interior das instituições do Estado, assim não incorrendo no erro apontado por Raffestin (1993) de ver o Estado como a única fonte do poder. Essas outras fontes do poder - ou, seria melhor dizer, que disputam o poder - incluem os agentes hegemônicos - como as grandes empresas - e os agentes não hegemônicos, que incluem a grande maioria dos movimentos sociais e todos aqueles que, não organizados na forma de "movimentos sociais", são invisibilizados pelos agentes hegemônicos.

A interdependência entre os subsistemas é clara, pois nenhum deles toma decisões de maneira unilateral, já que chegar a compromissos aceitáveis por todos constitui condição prévia de toda ação. Essa proposição, que tem um alto grau de generalidade, é acompanhada de uma segunda, que é um atributo dos sistemas de ação: nenhum compromisso é negociado diretamente entre as partes. As negociações sempre são operadas através da intervenção de instâncias de outra natureza - por exemplo, a Marcha dos Prefeitos em Brasília é organizada pela Confederação Nacional dos Municípios -, daí a importância de processos de integração e coordenação, através dos quais compromissos possam ser obtidos, ou seja, há mediações institucionais entre os subsistemas.

De uma maneira geral, nesse sistema, cada município age sozinho pelos canais que lhe são abertos, sem nexos mais orgânicos com os vizinhos, sem comunicação horizontal e sem criar um front regional comum; carecemos de uma "lugarização" da Federação - de baixo para cima -, que estabeleça solidariedades orgânicas que possam tornar a vida de relações mais compartida entre os municípios. Não é por outra razão que há incentivos à criação de arranjos institucionais municipais, como consórcios públicos e contratos de programas que incentivam a gestão associada de serviços públicos. Entretanto, apesar de avanços, o pacto federativo brasileiro está esgarçado, carente de mecanismos de coordenação federativa e marcado antes por ações competitivas do que cooperativas (BRANDÃO, 2008). A não cooperação é generalizada entre as municipalidades brasileiras, cada uma delas procurando resolver os seus problemas com os escalões dos estados e da União. Por isso a intervenção 
de uma instância exterior é crucial para, ao mesmo tempo, coordenar as unidades entre si e permitir que cada uma delas tenha acesso ao centro.

A constatação é a de que o sistema de ação federativo é mais cooperativo entre os diferentes (União, estados e municípios) do que entre os iguais (estados entre si e municípios entre si), em que ele é competitivo, apesar de a Constituição de 1988 ter previsto "canais de comunicação" entre os subsistemas nacionais.

Os "poderes periféricos" ou "poderes laterais" e as "elites do poder", apesar de serem externos à hierarquia administrativa de um poder público (federal, estadual ou municipal), porque não têm cargos nos governos, são considerados internos ao sistema de ações, porque têm poder para sugerir ou mudar uma política pública. Essa proposição teórica revela as forças do mercado - das grandes empresas - como internas às estruturas de poder. $\mathrm{O}$ sistema de ação interpreta os agentes sempre em "ação dinâmica" e nunca somente enquadrados pelas regras existentes, mas compreendidos em relação às suas tentativas de modificar e transformar as regras vigentes em seu favor. Enfim, o sistema de ação resulta de interações e interdependências e de processos de troca e de poder entre os agentes, servindo ao mesmo tempo para estabilizar, estruturar, canalizar e regular os pactos socioterritoriais federativos.

Como o sistema de ações não é isolado do sistema de objetos, nossa interpretação do federalismo como um sistema de ações permite incorporar a dimensão do território usado em sua formulação, não como discurso, não como substrato sobre o qual são operadas políticas públicas, mas como elemento ativo e condicionante do sistema de ações.

De fato, é dentro das fronteiras nacionais, do território nacional, que os processos e as estruturas encontram unidade. A questão que se coloca é a da elaboração de outra Federação, uma Federação lugarizada (SANTOS, 2000b), na qual se possam identificar formas pelas quais o conjunto dos lugares tenham um desenvolvimento harmonioso, uma solidariedade orgânica, e esse exercício precisa ser realizado tendo em vista uma compartimentação do território em áreas de identidade, legitimadas pelas suas próprias condições de existência local, que dificilmente coincidirão com as divisões político-administrativas. Para Santos (op. cit.), essa regionalização com base no cotidiano seria o fundamento da emergência de outro nível político-territorial, que permitiria enfrentar as articulações entre as esferas federativas e a multiplicidade de formas de uso do território que tensamente coexistem nos lugares.

Para isso, é preciso insistir, é necessário valorizar o conceito de território usado, que, diferentemente das ações estratégicas - forma dominante do exercício do poder hegemônico -, valoriza a vida de relações, valoriza o espaço de todos, de todas as práticas, de todos os usos da vida coletiva que é dirigida à defesa de valores culturais. 
Assim compreendido, o "território usado", um espaço banal, emerge como elemento de interlocução dos lugares com as instâncias de poder federativas. Dessa forma, as questões que se colocam são: (i) a identificação das arquiteturas pelas quais cada lugar possa ter um desenvolvimento solidário e harmonioso junto com os outros lugares dentro da Federação (SANTOS, 2000b), (ii) como a apropriação socialmente justa do espaço herdado pode proporcionar a objetivação e materialização de direitos no cotidiano, nos lugares usados, e como corolário dessas duas questões, (iii) como se coloca o problema do justo uso dos recursos públicos para uma mais digna consecução da vida de relações nos lugares.

\section{Conclusões}

Colocar o território usado no centro da análise federativa exige uma tarefa analítica: identificar e classificar objetos e ações (SANTOS, 1996), agentes e agidos (LATOUR, 1992), estabelecer a gênese e a atualidade dos atores, pois os mesmos só raramente têm a mesma idade no lugar, e encontrar as hierarquias entre os atores (GOLDMANN, 1972), já que eles não possuem idêntico poder de ação, tampouco têm as mesmas intencionalidades.

O território político-administrativo, que divide o país em estados e municípios, não é categoria de análise. A categoria de análise é o território usado (SANTOS, 1994), porque, além de incorporar as verticalidades federativas - os três entes da Federação -, inclui todos os poderes "periféricos", a vida de relações local, ou seja, as horizontalidades que, apesar de não fazerem parte institucional dos poderes públicos, analiticamente precisam ser consideradas em seus poderes de interferência nas políticas públicas.

\section{Nota}

1. "O espaço banal seria o espaço de todos: empresas, instituições, pessoas; o espaço das vivências. Esse espaço banal, essa extensão continuada, em que os atores são considerados na sua contiguidade, são espaços que sustentam e explicam um conjunto de produções localizadas, interdependentes, dentro de uma área cujas características constituem também um fator de produção. Todos os agentes são, de uma forma ou de outra, implicados, e os respectivos tempos, mais rápidos ou mais vagarosos, são imbricados" (Santos, 2000a, p. 109).

\section{Referências}

ABRÚCIO, F.L. Os barões da Federação. Os governadores e a redemocratização brasileira. São Paulo: Hucitec, 1998. 
AMARAL FILHO, J. Federalismo e recentralização fiscal-financeira no Brasil. In: JORNADAS INTERNACIONALES DE FINANZAS PÚBLICAS, 41., Anais... Córdoba: Faculdade de Ciências Econômicas da Universidade Nacional de Córdoba, set. 2008.

ARRETCHE, M. Democracia, federalismo e centralização no Brasil. Rio de Janeiro: FGV/Fiocruz, 2012.

BRANDÃO, C.A. Pactos em território: escalas de abordagem e ações de desenvolvimento. Revista OES, Salvador, v. 15, n. 45, p. 145-157, 2008.

BRANDÃO, C.A. A busca da utopia do planejamento regional. Revista Paranaense de Desenvolvimento, Curitiba, n. 120, p. 17-37, 2011.

BRAUDEL, F. Civilização material, economia e capitalismo, séculos XV-XVIII. III - O tempo do mundo. São Paulo: Martins Fontes, 1995.

BURZTYN, M. O poder dos donos. Vozes: Petrópolis, 1987.

CARDOZO, S.A. Continuidades e descontinuidades na articulação do espaço econômico nacional - 1930 aos anos 90: uma análise a partir das políticas tributária, monetária e de desenvolvimento regional. 2004. Dissertação (mestrado em Economia) - Instituto de Economia da Universidade Estadual de Campinas, Campinas.

CASTRO, I.E. O mito da necessidade. Discurso e prática do regionalismo nordestino. Rio de Janeiro: Bertrand Brasil, 1992.

CASTRO, I.E. Instituições e território. Possibilidades e limites ao exercício da cidadania. Revista Geosul, Florianópolis, v. 18, n. 36, p. 7-28, 2003.

CATAIA, M. Território nacional e fronteiras internas. A fragmentação do território brasileiro. 2001. Tese (doutorado em Geografia) - Faculdade de Filosofia, Letras e Ciências Humanas. Universidade de São Paulo, São Paulo.

CATAIA, M. Território usado e Federação: novos agentes e novos pactos. In: DANTAS, A.; TAVARES, M.A.A. (Org.). Lugar-mundo: perversidades e solidariedades. Encontros com o pensamento de Milton Santos. Natal: EDUFRN, 2011. p. 101-119.

CORBOZ, A. Le territoire comme palimpseste. Revue Diogène, Paris, n. 121, p. 14-35, 1983.

COUTO E SILVA, G. Geopolítica e poder. Rio de Janeiro: Univer-cidade, 2003.

CROZIER, M.; FRIEDBERG, E. L'acteuret le système. Paris: Éditions du Seuil, 1977.

FIORI, J.L. O federalismo diante do desafio da globalização. In: AFFONSO, R.B.A.; BARROS E SILVA, P.L. (Org.). A Federação em perspectiva: ensaios selecionados. São Paulo: Fundap, 1995. p. 19-38. 
FAORO, R. Os donos do poder. Formação do patronato político brasileiro. São Paulo: Globo/Publifolha, 2000.

FURTADO, C. Brasil. A construção interrompida. Rio de Janeiro: Paz \& Terra, 1992.

GALLO, F. Uso do território e federalismo como evento: a difusão regional de infraestruturas analisadas a partir das Transferências Intergovernamentais Voluntárias entre União e Municípios. 2011. Tese (doutorado em Geociências) - Instituto de Geociências da Universidade Estadual de Campinas, Campinas.

GOLDMANN, L. Dialéctica e ciências humanas I. Lisboa: Editorial Presença, 1972.

GOTTDIENER, M. A produção social do espaço urbano. São Paulo: Edusp, 1993.

GRÉMION, P. Le pouvoir périphérique: bureaucrates et notables dans le système politique français. Paris: Seuil, 1976.

HABERMAS, J. A constelação pós-nacional. Ensaios políticos. São Paulo: Littera Mundi, 2001.

HARVEY, D. A produção capitalista do espaço. São Paulo: Annablume, 2005.

KUGELMAS, E.; SOLA, L. Recentralização/descentralização. Dinâmica do regime federativo no Brasil nos anos 90. Tempo Social, São Paulo, v. 2, n. 11, p. 63-81, 2000.

LATOUR, B. Aramis ou l'amour des techniques. Paris: La Decouverte, 1992.

LATOUR, B. Jamais fomos modernos. Ensaio de antropologia simétrica. Rio de Janeiro: Editora 34, 1994.

LOPREATO, F.L.C. Caminhos da política fiscal do Brasil. 2011. Tese (livre docência) Instituto de Economia da Universidade Estadual de Campinas, Campinas.

MARKUSEN, A. Mudança econômica regional segundo o enfoque centrado no ator. In: DINIZ, C.C.; LEMOS, M.B. (Org.). Economia e território. Belo Horizonte: Editoria da UFMG, 2005. p. 57-75.

MILLS, C.W. A elite do poder. Rio de Janeiro: Zahar, 1962.

RAFFESTIN, C. Por uma geografia do poder. São Paulo: Ática, 1993.

RIBEIRO, A.C.T. Outros territórios, outros mapas. OSAL (Observatório Social de America Latina), Buenos Aires, ano 6, n. 16, 2005.

RIBEIRO, A.C.T. Territórios da sociedade: por uma cartografia da ação. In: SILVA, C.A. (Org.). Território e ação social: sentidos da apropriação urbana. Rio de Janeiro: Lamparina, 2011. p. 19-34.

SANTOS, M. O espaço do cidadão. 2. ed. São Paulo: Nobel, 1993. 
SANTOS, M. O retorno do território. In: SANTOS, M. et al. (Org.). Território: globalização e fragmentação. São Paulo: Anpur/Hucitec:, 1994. p. 15-20.

SANTOS, M. A natureza do espaço. Técnica e tempo, razão e emoção. São Paulo: Hucitec, 1996.

SANTOS, M. Por uma outra globalização. Rio de Janeiro: Record, 2000a.

SANTOS, M. Por uma nova Federação. Correio Braziliense, Brasília, DF, 16 jul. 2000 b.

SANTOS, M.; SILVEIRA, M.L. O Brasil. Território e sociedade no início do século XXI. Rio de Janeiro/São Paulo: Record, 2001.

SASSEN, S. Sociologia da globalização. Porto Alegre: Artmed, 2010.

SILVEIRA, M.L. O lugar defronte os oligopólios. In: DANTAS, A.; TAVARES, M.A.A. (Org.). Lugar-mundo: perversidades e solidariedades. Encontros com o pensamento de Milton Santos. Natal: EDUFRN, 2011. p. 79-100.

VAINER, C. As escalas do poder e o poder das escalas: o que pode o poder local? In: ENCONTRO NACIONAL DA ANPUR, 9., Anais... Rio de Janeiro, p. 140-151, 2001. Ética, Planejamento e Construção Democrática do Espaço; v. 1.

VIEIRA, D.J. Um estudo sobre a guerra fiscal no Brasil. 2012. Tese (doutorado em Economia) - Instituto de Economia da Universidade Estadual de Campinas, Campinas.

Recebido em 30 de outubro de 2013.

Aprovado em 29 de novembro de 2013. 
